\title{
Dificuldades no atendimento ao idoso: percepções de profissionais de enfermagem de unidades de saúde da família ${ }^{1}$
}

\author{
Laura Moreira de Sousa Fonseca*, Cléria Maria Lobo Bittar*
}

\section{Resumo}

$\mathrm{O}$ atendimento ao idoso requer competências e conhecimentos muitas vezes não suficientemente contemplados durante os anos de formação profissional, tornando comum o relato de dificuldades encontradas pelos profissionais na hora de lidar com essa população. Este estudo, de caráter qualitativo, teve como objetivos conhecer as percepções e as dificuldades relatadas por um grupo de profissionais de enfermagem sobre o atendimento ao idoso. Participaram deste estudo 12 profissionais da área de Enfermagem que atuavam na Unidade de Saúde da Família no município de Coromandel (MG), que responderam a um questionário elaborado pela autora, para essa finalidade. Os participantes relataram que viam o idoso como uma "pessoa sábia, com muita experiência de vida', que possuíam "vastos conhecimentos" e que eram capazes de dar "sábios conselhos". No entanto, apontaram que as maiores dificuldades para lidar com os idosos diziam respeito à falta de maiores conhecimentos sobre as necessidades e os cuidados com a faixa etária e, também, em relação à escassez de informação recebida durante a graduação, além de fatores outros, tais como o descaso dos familiares dos idosos, a dificuldade dos idosos na adesão aos tratamentos de saúde e a sobrecarga de trabalho. Conclui-se que, para atender a necessidade de meIhor preparar profissionais para lidar com a crescente demanda no atendimento ao idoso, torna-se necessário rever o conteúdo programático da formação profissional, e, em relação à queixa de sobrecarga de trabalho, é mister uma melhor organização e um planejamento adequado do trabalho, de modo a não comprometer tanto o atendimento prestado, assim como a saúde do próprio trabalhador.

Palavras-chave: Promoção da Saúde. Atenção Integral à Saúde do Idoso. Atenção Primária à Saúde. Enfermagem.

* Enfermeira. Mestre em Promoção de Saúde pelo Programa de Mestrado e Doutorado em Promoção de Saúde da Universidade de Franca, SP. Coordenadora do curso de Enfermagem da Faculdade Atenas de Paracatu (MG). E-mail: lauramoreirasf@hotmail.com

** Psicóloga. Docente do Programa de Mestrado e Doutorado em Promoção da Saúde e do curso de Psicologia da Universidade de Franca/Cruzeiro do Sul. E-mail: profa.cleriabittar@gmail.com

$\rightarrow$ http://dx.doi.org/10.5335/rbceh.2012.4080

Recebido em: 10/07/2014. Aprovado em: 03/11/2014 


\section{Introdução}

O envelhecimento populacional é um processo que vem acontecendo de forma acelerada. Um fenômeno mundial marcado pela transição demográfica, no qual se observa um grande aumento da população idosa. Esse processo de transição demográfica acontece graças aos grandes avanços tecnológicos e científicos, bem como ao processo de urbanização e à queda da taxa de fecundidade. Junto ao envelhecimento populacional, ocorreram também mudanças nas causas de morbidade - trazendo atualmente como consequência um novo perfil de mortalidade - e, paralelamente, um aumento das doenças crônicas degenerativas e a diminuição das doenças infectocontagiosas (CARMO; BARRETO; SILVA, 2003; BRASIL, 2006; SANTOS; SANTOS, 2012).

O envelhecimento é um fenômeno natural, um processo que se inicia desde o nascimento e perdura todo o ciclo vital e que vai apresentando alterações fisiológicas durante todo esse processo, com maior ênfase nas fases finais do ciclo, a meia idade e a velhice. São múltiplos os fatores que explicam o envelhecimento: "fatores moleculares, celulares, sistêmicos, comportamentais, cognitivos e sociais. Estes interagem e regulam tanto o funcionamento típico quanto o atípico do indivíduo que envelhece" (SANTOS; ANDRADE; BUENO, 2009, p. 8), devendo-se, portanto, avaliar o aspecto multidimensional envolvido no processo, em suas dimensões biológica, cronológica, psicológica e sociocultural.
O envelhecimento pode ser compreendido como um processo natural, de diminuição progressiva da reserva funcional dos indivíduos - senescência - o que, em condições normais, não costuma provocar qualquer problema. No entanto, em condições de sobrecarga como, por exemplo, doenças, acidentes e estresse emocional, pode ocasionar uma condição patológica que requeira assistência - senilidade. Cabe ressaltar que certas alterações decorrentes do processo de senescência podem ter seus efeitos minimizados pela assimilação de um estilo de vida mais ativo (BRASIL, 2006, p. 8).

Essas alterações fisiológicas, comuns ao processo, deixam o idoso mais vulnerável a incapacidades físicas, mentais e funcionais, além de aumentar a susceptibilidade a adoecimentos típicos dessa fase, como os quadros de degeneração neurofisiológicas, osteoporose, acidente vascular cerebral, hipertensão arterial, câncer de próstata, de pele e de cólon, catarata, além de maior propensão à quedas, pela razão da dificuldade em manter equilíbrio (ERMIDA, 1999; FREITAS et al., 2010; FREITAS; PY, 2011; BRASIL, 2012; ESQUENAZI; SILVA; GUIMARÃES, 2014).

Devido ao processo natural do envelhecimento, o idoso faz parte de um grupo de risco que exige um tipo de atendimento diferenciado e altamente qualificado, tornando-se imprescindível que os profissionais busquem maiores conhecimentos sobre o processo natural do envelhecimento e das patologias a ele relacionadas (SANTOS, ANDRADE, BUENO, 2009; MENDES et al., 2012).

Os cuidados de saúde indispensáveis à população idosa demandam investimentos significativos na reestruturação e na readequação de recursos físicos, 
instalações e equipamentos, além de medicamentos, pessoal capacitado, procedimentos tecnológicos, desenvolvimento, planejamento e gestão do sistema de saúde (GOLDMAN, 2004; FERREIRA et al. 2012; SILVA; YAZBEK, 2014), o que implica uma grande transformação da sociedade, trazendo uma série de consequências sociais, culturais, econômicas, políticas e epidemiológicas para as quais o país deve se preparar.

Até a década de 1960, não eram oferecidos programas ou serviços de qualquer natureza aos idosos em melhores condições socioeconômicas, bem como aos que não necessitavam recorrer ao asilamento (COSTA et al., 2011; BRASIL, 2010). Desse modo, esses idosos, de uma forma geral, encontravam-se isolados e excluídos da sociedade, tanto pela perda das funções profissionais - associados às imagens preconceituosas atribuídas tanto à velhice e à aposentadoria (FÔLHA; NOVO, 2011), quanto pela ausência de um papel econômico e/ou social, e pelo pouco interesse da sociedade com a questão social da velhice (ROZENDO, 2010).

De acordo com Freitas et al. (2010), a estratégia dos programas de saúde para a população idosa é a prevenção das doenças e promoção da saúde do idoso, pois essas são as alternativas para um envelhecimento ativo e de qualidade. Diante do crescente envelhecimento populacional, programas de promoção da saúde do idoso são cada vez mais idealizados. Sendo assim, há necessidade de planejar estratégias que proponham uma assistência de qualidade às peculiaridades dessa etapa do ciclo vital, que tenham resolutividade efetiva e concreta em se tratando de promoção, prevenção e manutenção da saúde desse segmento da população (MOREIRA; JALLES; REINALDO, 2007; FERREIRA et al., 2012).

No Brasil, o processo do envelhecimento aconteceu de forma acelerada e modificou drasticamente a pirâmide populacional, originando uma demanda acentuada por serviços característicos desse grupo etário (VERAS, 2003; SILVA, 2005; CARVALHO; WONG, 2008; LEBRÃ, 2009). Com o intuito de fomentar o debate sobre a qualificação dos profissionais para o atendimento ao idoso, este estudo buscou conhecer as percepções e as dificuldades que os profissionais da área de enfermagem tinham a respeito do atendimento ao idoso e como lidavam com essas.

Este artigo é parte da discussão de uma pesquisa realizada no programa de mestrado em promoção de saúde e apresentará duas das quatro categorias temáticas encontradas nos resultados.

\section{Método}

Trata-se de um estudo descritivo-qualitativo com a finalidade de verificar quais as dificuldades e as percepções sobre $o$ atendimento aos idosos dos profissionais de Enfermagem (enfermeiro, técnico e auxiliares de enfermagem) que atuavam nas USF do município de Coromandel-MG. A escolha pelo método qualitativo se deu por entender que esse oferece um tipo de investigação cujas técnicas especializadas em obter respostas sobre os pensamentos e sentimentos das pessoas, permitem melhor compreensão das atividades, crenças e comporta- 
mentos dos participantes (BOGDAN; BIKLEN, 1994; MINAYO, 2006).

$\mathrm{O}$ estudo foi realizado no município de Coromandel (MG) que, segundo o censo demográfico registrou, tem 27.551 habitantes (IBGE, 2010), com seis mil famílias cadastradas no Sistema de Informação de Atenção Básica (SIAB), atendidas nas cinco Unidades de Saúde da Família (USFs), segundo os dados do Cadastro Nacional de Estabelecimento de Saúde (CNES). Os dados são de julho de 2010. O projeto respeitou o teor da Resolução 466/12, sendo aprovado pelo Comitê de Ética e Pesquisa (Cepe) da Universidade de Franca (Protocolo $n^{\circ}$ 4705/10).

Inicialmente, foi realizado um estudo piloto com cinco profissionais de enfermagem das USFs que não fizeram parte do estudo principal por não se enquadrarem nos critérios de inclusão, com o intuito de aprimorar e corrigir as questões. $\mathrm{O}$ estudo piloto foi submetido à apreciação de três juízes - sendo todos docentes do programa de Mestrado em Promoção de Saúde e da área da Enfermagem, que apontaram sugestões para o questionário final. Adotou-se como instrumento de coleta de informações, um questionário que continha duas questões fechadas e seis questões abertas sobre as percepções e as dificuldades dos profissionais de enfermagem sobre $o$ atendimento ao idoso. As respostas registraram a percepção e o conhecimento que os profissionais apresentaram sobre os idosos e como se sentiam em relação ao atendimento a esses.

Para realização do presente estudo, foram convidados para participar desta pesquisa todos os quinze profissionais de Enfermagem (enfermeiros, técnicos e auxiliares) que atuavam nas cinco Unidades de Saúde da Família (USFs) do município de Coromandel, mas, desses, somente 12 participaram. Adotou-se como critério de inclusão os profissionais que atuavam nas USFs há pelo menos um ano e que aceitaram participar de forma voluntária da pesquisa, sendo excluídos os profissionais que tinham menos de um ano de atuação na USF.

Os 12 participantes eram $(\mathrm{n}=7)$ auxiliares de enfermagem, $(n=1)$ técnico de enfermagem e $(n=4)$ enfermeiros, identificados como P1, P2, e assim sucessivamente até o último participante, P12. Os Termos de Compromisso Livre e Esclarecidos (TCLE) foram entregues pela pesquisadora e recolhidos devidamente preenchidos antes da entrega dos questionários de modo a não associá-los, preservando-se o anonimato. Os questionários, respondidos foram colocados em uma urna fechada, deixada pela pesquisadora em cada USF, sendo posteriormente recolhidas pela pesquisadora.

As questões versavam sobre as percepções e as dificuldades mais comuns que os profissionais enfrentavam no atendimento ao idoso, e o que faziam para superá-las.

\section{Análise e discussão dos resultados}

A análise das questões fechadas sobre a formação profissional e o tempo de sua atuação na Unidade de Saúde da Família (USF), demonstrou que, dos 12 participantes, oito atuam há mais de cinco anos na USF, dois atuam há 
menos de dois anos e, outros dois, entre três e quatro anos. Ressalta-se que não se distinguiu os participantes por suas respectivas áreas profissionais, por questões éticas, uma vez que, em alguns casos, um único participante representava sua categoria, o que poderia colocá-lo em evidência. $\mathrm{O}$ mesmo cuidado foi tomado em relação ao sexo, uma vez que apenas um participante era do sexo masculino. Após leitura exaustiva das respostas, foram formuladas quatro categorias, agrupadas por temas. Neste artigo, serão discutidas apenas duas categorias temáticas: Categoria 1 - Idosos: sabedoria X fragilidade e Categoria 2 - Dificuldades e superação no atendimento ao idoso.

Para a construção da primeira categoria, foi analisada a resposta da questão: "Como você vê o idoso?", e, para a segunda categoria, foram analisadas as respostas da questão: "Quais são as dificuldades mais comuns que você enfrenta no atendimento ao idoso, e o que faz para superá-las?".

De acordo com Navarrete e Silva (2009), a análise de dados implica três etapas básicas: a primeira é a fase de descobrimento na qual se identificam temas e se desenvolvem conceitos de ideias; a segunda fase inclui a classificação dos dados e o refinamento da compreensão do tema estudado; na fase final, o pesquisador procura relativizar seus achados, buscando compreender os dados no contexto em que foram coletados e os interpreta. Na transcrição das falas, manteve-se a estrutura original dos participantes, buscando maior fidelidade.

\section{Categoria 1 - Idosos: sabedoria X fragilidade}

A maioria dos participantes vê o idoso como um ser sábio, com muitos conhecimentos, experiente e capaz, mas também frágil, carente e sofrido.

Vejo-o como uma pessoa que trabalhou e sofreu muito na vida, e ao longo desta adquiriu uma enorme experiência e que os mesmos possa repassar para as próximas gerações (P7).

Vejo-o como uma pessoa forte em experiência de vida, sábio no conselho aos jovens e ao mesmo tempo, carente da compreensão, da paciência de muitos que os exclui do convívio familiar (P8).

Uma pessoa fragilizada pelo tempo, mas que são capazes de responder pela sua própria pessoa e que traz exemplos para a gente (P9).

Os longos anos de vida, de trabalho pesado e as más condições de vida os tornaram frágeis pela perda da saúde e pelo envelhecimento, o que implica a necessidade de "cuidados diferenciados".

É uma pessoa que tem de ser atendido de forma diferente, mas eles têm muita coisa para oferecer (P10).

É um indivíduo diferenciado com plena capacidade, mas que muitas vezes vai apresentar fragilidades e alterações na saúde necessitando de acompanhamento constante, inclusive da família (P2).

Com a idade aumenta-se a probabilidade de desenvolver uma ou mais doenças crônico-degenerativas, o que pode desencadear complicações na qualidade de vida da pessoa, afetando a funcionalidade e aumentando a dependência que geralmente, recai sobre alguém da família (CAMARANO, 2010; SANTOS, SANTOS, 2012) que, na maioria das 
vezes, não está preparado para assumir essa nova realidade.

Ressalta-se o "saber empírico", o conhecimento e a sabedoria dos idosos, que pode ser um fator para a contribuição para a sociedade como um todo, devendo, por isso, receber o devido reconhecimento e valor.

Sabe-se que os idosos já detentores de vasto saber empírico que pode ser sistematizado (saúde, social, cultural, culinária), sendo de grande importância para o presente. $\mathrm{O}$ idoso ocupa lugar de destaque, na sociedade, tendo em vista a trajetória de vida dessas pessoas (P4).

É uma pessoa que possui muitos conhecimentos, tendo vivenciado muitas experiências ao longo de sua vida. Faz parte de um ciclo da vida onde as habilidades físicas, mentais, sociais podem estar fragilizadas; mas que independentemente de sua condição ou grau de instrução deve ser respeitado e valorizado (P1).

Os participantes P3, P11 e P12 veem o idoso como um ser dependente, que necessita de cuidados especiais, como carinho, atenção e afeto, por parte dos profissionais e familiares.

É uma pessoa que precisa de 'cuidados' especiais, atenção, carinho e afeto (P3).

$\mathrm{O}$ idoso é um cliente que requer maior atenção por parte dos profissionais de saúde; deve-se conhecer o idoso e sua família para atuar de forma a garantir um atendimento eficiente. Deve-se ter paciência e atenção nas explicações para que haja um bom entendimento (P11).

(...) como uma pessoa carente de afeto e de atenção social e familiar. É dependente de maior atenção na saúde (P12).

É uma pessoa que já trabalhou muito, que necessita de atenção, atendimento adequado pelos profissionais de saúde e pelos familiares (P6).
$\mathrm{O}$ participante $\mathrm{P} 5$ reconhece que atualmente o idoso tem maior acesso aos serviços de saúde e está mais esclarecido de seus direitos.

$\mathrm{O}$ idoso hoje tem mais facilidade quanto ao atendimento médico, a sua alimentação, existe mais serviços para o mesmo. Pessoal capacitado para atendê-lo. O idoso hoje está mais esclarecido (P5).

Ainda que muito tenha a ser feito, é inegável que o amparo legal aos direitos dos idosos, como por exemplo as publicações da Política Nacional do Idoso (BRASIL, 1994) e do Estatuto do Idoso (BRASIL, 2003), a Portaria 2.2528/2006, que aprova a Política Nacional de Saúde da Pessoa Idosa (BRASIL, 2006), entre outros documentos, foram importantes conquistas da sociedade brasileira, que, aos poucos, começa a conhecê-los melhor e se conscientizar de seus direitos e deveres.

Na percepção de Veras (2012), os modelos vigentes de saúde são de alto custo e ineficientes, demandando novas estruturas inovadoras.

É por este motivo que, do ponto de vista da saúde pública, a capacidade funcional surge como o conceito de saúde mais adequado para instrumentalizar e operacionalizar uma política contemporânea de atenção à saúde do idoso. Essa política deve, portanto, ter como objetivo maior a manutenção da máxima capacidade funcional do indivíduo que envelhece, pelo maior tempo possível.

Quanto à maior oferta de atendimento médico, salienta-se que além desse fato, torna-se necessário que a atenção primária nas USFs tenha melhor resolubilidade e acessibilidade (ELIAS et al., 2006), lembrando que a Unidade 
de Saúde da Família (USF) constitui-se em porta de entrada para os serviços de saúde, facilitando o acesso para alguns idosos, devendo receber, portanto, maiores cuidados por parte dos gestores.

\section{Categoria 2: Dificuldades e superações no}

\section{atendimento ao idoso}

O que se buscava, a priori, era saber quais dificuldades pessoais o profissional tinha no atendimento ao idoso, e como acreditava poder saná-las. A maioria dos participantes acreditava que as capacitações e a busca por mais formação e conhecimento, era uma forma de lidar com essas dificuldades. Ressalta-se a fala de dois participantes (P6 e P11) que entendiam ser a falta de apoio dos familiares as principais dificuldades enfrentadas no atendimento ao idoso.

$\mathrm{O}$ descaso de alguns familiares para acompanhar os idosos e auxiliar os mesmos em suas necessidades, e no acompanhamento com a medicação. E para sanar esse fato, tem que orientar da importância dos cuida$\operatorname{dos}(\mathrm{P} 6)$.

A falta de compromisso dos familiares com o idoso (P11).

Conhecer a realidade desses familiares, saber suas reais condições para cuidar de seus idosos, saber como é a convivência entre eles, torna-se um objetivo a ser alcançado.

Os participantes P7, P5 e P2 diziam ter dificuldades com a resistência do próprio idoso à adesão ao tratamento. Isso acontece frequentemente, pois muitas vezes fazem uso de muitas medicações ou há necessidade de uma dieta rigorosa $\mathrm{e}$ o idoso tende a resistir a seguir o tratamento corretamente. $\mathrm{O}$ participante $\mathrm{P} 2$ ainda ressaltou o esquecimento do idoso e a falta de acompanhante nas consultas, o que também implica uma dificuldade. "É que muitos não aceitam ajuda, pois acreditam poder se cuidar sozinho". (P7)

$\mathrm{E}$ acrescenta o participante que, para lidar com isso, era necessário: "Paciência, carinho e compreensão" (P7).

Às vezes é difícil para o próprio idoso aceitar que necessita de alguém para acompanhá-lo e ajudá-lo no dia a dia. Procuro então, me capacitar (P5).

As limitações fisiológicas - como a perda da memória, além da falta de adesão ao tratamento, foram motivos apontados como dificuldades, e o incentivo aos atendimentos com acompanhantes e visitas domiciliares foram as formas de melhor lidar com a problemática, conforme disse um participante.

$\mathrm{O}$ esquecimento por parte do idoso. Muitas vezes o idoso chega para o atendimento sem acompanhamento e não sabe precisar a forma como está realizando o tratamento medicamentoso ou mesmo o que está sentindo. $\mathrm{O}$ que acarreta a falta de adesão ao tratamento por longos períodos. Para resolver [isso] incentivo $o$ atendimento com acompanhante e visitas domiciliares de supervisão (P2).

Para o participante P8, sua personalidade extrovertida contrastava com a da maioria dos idosos e relata como fazia para superar sua dificuldade.

Por eu ser muito extrovertida, minha dificuldade é até me adaptar ao gênio do mesmo, pois sei que nem todos gostam, ou seja, há alguns de gênio forte, mais fechados. Procuro ser eu mesma e procuro me adaptar a ele, já que seria muito difícil ele se adaptar a mim (P8). 
A dificuldade de comunicação entre equipe e idosos é, para os participantes P3 e P9, a maior dificuldade que enfrentam no atendimento, sobretudo pelas peculiaridades físicas e cognitivas que $o$ idoso tem que, às vezes implicam maior dificuldade de compreensão.

Dificuldade de compreensão, dificuldade de execução das orientações passadas pelos profissionais de saúde (P3).

A dificuldade de comunicação com o idoso, a dificuldade que eles têm de entender o que é orientado a eles. Tem que ter paciência, explicar várias vezes até ele entender (P9).

Morais et al. (2009) relatam que a comunicação intrapessoal é fundamental e é influenciada pelo conceito de valorização e pelos sentimentos. Quando se trata de cuidados, a comunicação influencia muito, à medida que se consegue ampliar as demandas e compreender melhor os idosos, o que auxilia a estabelecer uma relação de ajuda e de confiança. A dificuldade do idoso em entender o que lhe é orientado/informado é algo que alguns participantes descreveram enfrentar durante $o$ atendimento. Cabe aos profissionais proporem formas ou alternativas de melhorar essa comunicação para facilitar-lhes a compreensão, buscando exemplos práticos que facilitem tanto a comunicação, como a compreensão do trabalho profissional. Aqui novamente deve ser levado em conta, além da experiência profissional, o tipo de conhecimento e informação que se recebeu durante os anos de formação acadêmica.

Sabemos que a atuação da equipe de enfermagem nas Unidades de Saúde da Família, cujo trabalho é multidisciplinar, torna o profissional um importante elo de comunicação entre toda a equipe e usuários. Sobre sua atuação, Araujo e Oliveira (2009, p. 6) comentam:

A ação de enfermagem tem se tornado essencial comunicação com os outros membros da equipe de saúde em relação às condutas adotadas no atendimento ao usuário, tomando por base o fato de que em qualquer campo do saber no trabalho em equipe as informações não são exclusivas a um único membro. Cada profissional conhece o seu limite e tem legitimadas suas ações na legislação que lhe respalda, e não deve se propor a realizar ações fora do alcance da sua competência ou de suas possibilidades profissionais.

Os participantes $\mathrm{P} 10$ e P12 dizem que a maior dificuldade por eles enfrentada no atendimento ao idoso é a falta de tempo, pois são sobrecarregados e não dispõem do tempo que esse grupo necessitaria para ser bem atendido; os idosos são carentes de conversa, querem relatar suas queixas, mas os profissionais não têm o tempo necessário para lhes dar essa atenção. Os participantes relatam buscar sanar essas dificuldades com paciência demonstrando interesse mesmo ante o tempo escasso.

A falta de tempo, pois eles são carentes, querem conversar e não podemos dar a atenção necessária por falta de tempo. Busco demonstrar interesse pelos seus problemas, mesmo quando estou apressada (P10).

A falta de tempo para ouvir suas queixas e seus temores. Tem que ter cuidados específicos para lidar com as deficiências de cada um; dedicação, paciência e profissionalismo (P12).

$\mathrm{O}$ participante $\mathrm{P} 1$ relata que as principais dificuldades no atendimento ao idoso, relacionam-se com a resistência ao tratamento devido às crenças, como 
por exemplo, a "benzição", além do fato de que os idosos necessitam de maior atenção, rapidez e agilidade no atendimento, o que muitas vezes contraria a própria demanda da unidade de saúde.

A “urgência” que o idoso tem de ser atendido no momento dele, e não na demanda da unidade de saúde. A resistência em colaborar com a proposta terapêutica principalmente adesão ao uso de medicamentos em virtude de práticas culturais como a "benzição" (P1).

Em seguida, esse mesmo participante apresenta o que ele faz para superar as dificuldades que apresentou.

Implantamos na USF para atendimentos programados horários preestabelecidos, diminuindo o tempo de espera. Procuramos esclarecer tanto nos grupos quanto individualmente a necessidade do uso correto dos medicamentos associados às práticas culturais; demonstrando respeito a estas práticas e ganhando o respeito de nossos pacientes e fortalecendo vínculos (desde que não nocivos à saúde) (P1).

No mesmo sentido do participante anterior, para P3, as "crenças não orientadas", ou seja, aquelas sem fundamento e lógica clínica ou científica, também eram tidas como dificuldades no atendimento ao idoso, apontando como alternativa desmitificá-las, mas não sem antes apontar a necessidade do vínculo com o paciente ser mais forte, com a finalidade de se "Criar mais vínculo com o paciente, para a desmistificação de crenças não orientadas" (P3).

Nota-se a complexidade do tema abordado e o quanto são variadas as dificuldades enfrentadas por esses participantes, como é relatado por $\mathrm{P} 4$, que diz que a maior dificuldade está em atender idosos com dificuldades psicológicas (deprimidos, rebeldes) e aqueles que se sentem excluídos socialmente, devido às limitações por parte do sistema de saúde, que não oferecem recursos necessários para o atendimento ao idoso nessas condições.

Idosos deprimidos/rebeldes, idosos que se sentem exclusos socialmente. O Sistema Único de Saúde (SUS) fornece poucos recursos (humanos, materiais, físicos) e- ou o SUS não está tendo uma gestão adequada (P4).

Além da dificuldade no atendimento aos idosos deprimidos e rebeldes, o participante comenta da dificuldade do próprio sistema de saúde, que, segundo sua visão, deixa a desejar. De acordo com Veras (2012), o aumento da população idosa no país obriga a uma reorganização do sistema de saúde no Brasil, o que determinará se os gastos com a saúde serão aplicados mais na manutenção dessa do que no tratamento de enfermidades ou dependência.

A prevenção e o retardamento de doenças e fragilidades, a manutenção da saúde, a independência e a autonomia em uma população mais velha serão os maiores desafios relacionados à saúde decorrentes do envelhecimento da população. Assim, qualquer política social e de saúde destinada aos idosos deve levar em conta a promoção da saúde e a manutenção da capacidade funcional (VERAS, 2012, p. 232).

Quanto aos recursos humanos no atendimento aos idosos, a Política de Humanização e Acolhimento à Pessoa Idosa preconiza, que essa relação

[...] pressupõe a mudança da relação profissional/usuário e sua rede social. Implica o compartilhamento de saberes, necessidades, possibilidades, angústias constantemente renovados (BRASIL, 2006, p. 14). 
A atenção básica à saúde do idoso tem como requisito oferecer à pessoa idosa e à sua família atenção humanizada, respeitando sempre sua cultura e influenciando o envelhecimento ativo, conforme estabelece a Estratégia de Saúde da Família (BRASIL, 2006), o que nem sempre é almejado.

Considerando-se o fato apresentado pelo participante, sabe-se que a velhice é, em si, é um fator que justifica a exclusão social dos idosos, que vivem em uma sociedade que valoriza os aspectos e o modus vivendi dos jovens (RIGUEIRA JUNIOR, 2008; LIMA et al., 2010), em uma cultura que valoriza uma intensa "juvenilização da velhice" (COUTO, MEYER, 2011, p. 22).

Como a inserção do idoso na sociedade é carregada de estigmas, ainda é aceito num contexto social aquele que estiver em condições ativas, gozando de boa saúde e contribuindo, seja econômica ou socialmente, para com a mesma. Por sua vez, aquele que se encontra em situação de intensa fragilidade é considerado sem grande valia e acaba por ser tratado d maneira preconceituosa e discriminatória, o que o coloca numa condição de vulnerabilidade social (SANTIN, BOROWSKI, 2008, p. 145).

Soma-se a isso o fato de que, com a idade, tem-se a aposentadoria, situação em que a maioria dos idosos deixam de ser produtivos e deixam de ter o poder de compra, muitas vezes sendo vistos como um peso para família e a sociedade, por estarem fora do mercado, fazendo com que a pessoa perca o seu valor social. "A associação da aposentadoria com o envelhecimento acaba trazendo à tona uma série de preconceitos voltados para o trabalho dos mais velhos e específi- cos do envelhecimento estereotipado" (FRANÇA, 2002, p. 24). Tal situação pode resultar em um processo gradual de solidão, de isolamento e de consequente depressão.

Sobre como lidar com algumas dessas dificuldades, o participante $\mathrm{P} 4$ busca saná-las aprimorando seus conhecimentos de enfermagem, promovendo grupos para trocarem experiências de conhecimentos diferenciados com objetivo de oferecer um atendimento de qualidade.

Estar me capacitando em vários conhecimentos de enfermagem, promovendo grupos operativos de pessoas idosas com temas que possam contribuir para adquirirem melhor qualidade de vida. Ouvir sempre os conhecimentos empíricos dos idosos e associar com o conhecimento já adquirido. Promover um atendimento de qualidade, com objetivo de resolutividade na manutenção de saúde (P4).

Como se observou, algumas respostas apontam o próprio idoso, seus familiares, ou o sistema de saúde - como também a falta de tempo e o excesso de trabalho -, pelas dificuldades mais comuns no atendimento ao idoso. Percebe-se que as dificuldades para o atendimento ao idoso são várias e de diversas dimensões desde o tempo que deve ser maior para o atendimento ao idoso até mesmo o aumento do conhecimento científico e habilidades técnicas que são necessárias para o cuidado com os idosos, passando pelo desafio em lidar com os familiares desses, para que sejam mais colaborativos e participantes quanto aos cuidados com o familiar idoso, colaborando para recuperação, prevenção e promoção da saúde desses. É verdade também que os participantes apontaram muitas formas com as quais lidam ou contornam essas 
dificuldades, incentivando a participação familiar no cuidado ao idoso e nas visitas domiciliares, com o intuito de planejarem estratégias e ações de autocuidado com os idosos, participando mais frequentemente de cursos de capacitação e ampliando o conhecimento em sua área. Com isso, buscam uma forma de enfrentamento desses obstáculos, pleiteando um resultado positivo na atenção ao idoso. Pode-se notar como a percepção dos participantes sobre o idoso se diferencia se comparada às respostas dadas na primeira categoria, em que se percebem um idoso muito "idealizado".

$\mathrm{Na}$ segunda categoria, quando questionados: "Quais são as dificuldades mais comuns que você enfrenta no atendimento ao idoso e o que faz para superá-las?", nota-se que os participantes têm outra percepção do idoso, apresentando aqui como sendo mais frágeis e dependentes, pois na prática o profissional sente as debilidades no atendimento à referida população, dificuldades que perpassam a própria atuação, as condições do trabalho, as limitações da estrutura, e a própria formação profissional que não lhes prepara adequadamente para a lidar com o idoso.

\section{Considerações finais}

Se inicialmente os participantes entenderam os idosos como seres dotados de conhecimento e sabedoria, credores, portanto, do reconhecimento e da necessidade de maior valorização social por sua contribuição à sociedade; também o reconheceram como indivíduos vulneráveis e frágeis, demandando um atendimento "diferenciado", que contemple suas vicissitudes. As maiores dificuldades estão na atenção e na capacitação profissional e na estrutura de atendimento oferecida à pessoa idosa. É mister repensar, portanto, a formação acadêmica e a capacitação profissional para 0 atendimento às demandas desse grupo populacional, para que o futuro profissional possa contemplá-las. Torna-se, desse modo, necessária a revisão dos conteúdos programáticos das disciplinas oferecidas nas formações profissionais, de forma que ofereçam o conhecimento e as técnicas que se fazem necessários para a atuação nesse grupo, não se esquecendo de incluir o papel da família para garantir que essa assistência possa ser integral e interdisciplinar.

Apesar da limitação deste estudo quanto à discussão das políticas e da gestão pública em saúde, o estudo revelou a necessidade de melhor organizar e reestruturar o atendimento à pessoa idosa. Evidenciou, ainda, a necessidade de melhor distribuir o tempo, fator que é relacionado à questão da sobrecarga de da equipe profissional, o que compromete, por um lado, o atendimento aos idosos e, por outro, a própria saúde do trabalhador.

Há, igualmente, a necessidade de ampliar a rede de assistência aos idosos em todos os níveis de atenção, otimizando o atendimento prestado nas USFs, uma vez que são os equipamentos mais próximos no atendimento à saúde, sendo a "porta de entrada" para a atenção em saúde. Dessa forma, em relação à pessoa idosa, reconhece-se em suas especificidades e particularidades, seu direito a uma vida digna, que lhe garanta mais qualidade de vida e bem-estar. 
Difficulties in the elderly care: perceptions of professional nursing of family health unit

\section{Abstract}

Elderly care requires skills and knowledge often not sufficiently covered during the years of vocational training, making common reporting difficulties by professionals when dealing with this population. This qualitative character study aimed to know the perceptions and the difficulties reported by a group of nursing professionals on elderly care. Participated in this study 12 nursing professionals operating in family health unit in the municipality of Coromandel, Minas Gerais, who responded to a questionnaire elaborated by the author, for this purpose. The participant reported that they saw the elderly as a "wise person, with a lot of life experience", with "extensive knowledge" and who were able to give "sage advice". However showed the biggest difficulties in dealing with the elderly, concerned the lack of greater knowledge about the needs and care of this age and the scarcity of information received during graduation, in addition to other factors, such as the neglect of the elderly relatives, the difficulty of the elderly on adherence to health treatments and work overload. It is concluded that to attend the needs for better prepare professionals to cope with the growing demand in elderly care, it becomes necessary to review the programmatic content of vocational training, and, in relation to complaint from work overload, is necessary a better organization and planning of the work, so as not to compromise either the service provided, as the health of the workers themselves.

Keywords: Health promotion, Integral attention to Elderly health and primary health care, nursing.

\section{Nota}

1 Estudo com apoio de Prosup/Capes.

\section{Referências}

ARAÚJO, M. S. F.; OLIVEIRA, F. M. C. A. Atuação do enfermeiro na equipe da família e a satisfação profissional. Caos, João Pessoa, n. 14, p. 3-14, set. 2009. Disponível em: <http://www.cchla.ufpb.br/caos/n14/ DOSSIE\%20SA\%C3\%9ADE_TEXTO\%20I_ ATUA\%C3\%87\%C3\%830\%20DO\%20ENFERMEIRO.pdf>. Acesso em: 2 jul. 2014.

BOGDAN, R.; BIKLEN, S. Características da investigação qualitativa. In: Investigação qualitativa em educação: uma introdução à teoria e aos métodos. Porto, Porto Editora, 1994. p. 47-51.

BRASIL. Lei n. 8.842, de 4 de janeiro de 1994. Dispõe sobre a Politica Nacional do doso, cria o Conselho Nacional do Idoso e dá outras providências. Disponível em: <http:// www.pbh.gov.br/leisdeidosos/politica federal-dec1948.htm>. Acesso em: 2 out. 2014.

Lei no 10.741 , de $1^{\circ}$ de outubro de 2003. Dispõe sobre o Estatuto do Idoso e dá outras providências. Disponível em: <http:// www.planalto.gov.br/ccivil_03/leis/2003/ 110.741.htm>. Acesso em: 29 set. 2014.

Política Nacional de Saúde da Pessoa Idosa. Brasília, DF, 2006. Disponível em: <http://dr2001.saude.gov.br/sas/PORTARIAS/Port2006/GM/GM-2528.htm>. Acesso em: 13 jun. 2014.

Ministério da Saúde. Secretaria de Atenção à Saúde. Departamento de Ações Programáticas e Estratégicas. Área Técnica Saúde do Idoso. Série Pactos pela Saúde 2006, v. 12, Brasília, 2010.

Ministério da Saúde. País investe em prevenção a doenças da terceira idade. Disponível em: <http://www.brasil.gov.br/ saude/2012/04/pais-investe-em-prevencao- 
-a-doencas-da-terceira-idade>. Acesso em: 1 out. 2014.

CAMARANO, A. A. Cuidados de longa duração para a população idosa: um novo risco social a ser assumido? Rio de Janeiro: Ipea, 2010.

CARMO, E. H.; BARRETO, M. L.; SILVAJR. Mudanças nos padrões de morbimortalidade da população brasileira: os desafios para um novo século. Epidemiol. Serv. Saúde, Brasília, v. 12, n. 2, p. 63-75, abr./jun. 2003. Disponível em: <http://scielo.iec.pa.gov.br/ scielo.php?script=sci_arttext\&pid=S1679$-49742003000200002 \& \operatorname{lng}=e n \& n r m=i s o>$. Acesso em: 15 out. 2014.

CARVALHO, J. A. M.; WONG, L. L. R. A transição da estrutura etária da população brasileira na primeira metade do século XXI. Cadernos de Saúde Pública, Rio de Janeiro, v. 24, n. 3, p. 597-605, mar. 2008.

COSTA, N. E.; MENDONÇA, J. M.; ABIGALIL, A. Políticas de assistência ao idoso: a construção da política nacional de atenção à pessoa idosa no Brasil. In: FREITAS, E. V. PY, L. et al. Tratado de geriatria e gerontologia. 3. ed. Rio de Janeiro: Guanabara Koogan, 2011. p. 1077-1082.

COUTO, E. S.; MEYER, D. E. Viver para ser velho? Cuidado de si, envelhecimento e juvenilização. R. FACED, Salvador, n. 19, p. 21-32, jan./jun. 2011. Disponível em: <http:// www.portalseer.ufba.br/index.php/entreideias/ article/view/5518/4297>. Acesso em 20 out. 2014.

ELIAS, P. E. et al. Atenção básica em saúde: comparação entre PSF e UBS por extrato de exclusão social no município de São Paulo. Ciência e Saúde Coletiva, São Paulo, v. 11, n. 3, p. 633-641, mar. 2006. Disponível em: $<$ http://www.scielo.br/scielo.php?script=sci arttext\&pid=S1413-81232006000300012\&ln $\mathrm{g}=\mathrm{en} \& n \mathrm{~nm}=\mathrm{iso}>$. Acesso em: 21 jun. 2014.

ERMINDA, J. G. Processo de Envelhecimento. In: COSTA, M. A. M. et al. (Org.). O Idoso: problemas e realidades. Coimbra: Formasau, 1999. p. 41-50.
ESQUENAZI, D.; SILVA, S. B; GUIMARÃES, M. C. M. Aspectos fisiopatológicos do envelhecimento humano e quedas em idosos. Revista HUPE, Rio de Janeiro, v. 13, n. 2, p. 11-20, 2014. Disponível em: < https:// www.e-publicacoes.uerj.br/index.php/revistahupe/article/view/10124/9623>. Acesso em: 20 out. 2014.

FERREIRA, O. G. et al. Envelhecimento ativo e sua relação com a independência funcional. Texto Contexto Enferm, Florianópolis, v. 21, n. 3, p. 513-518, jul./set. 2012. Disponível em: <http://www.scielo.br/pdf/tce/ v21n3/v21n3a04>. Acesso em: 14 out. 2014.

FÔLHA, F. A. S; NOVO, L. F. Aposentadoria: significações e dificuldades no período de transição a essa nova etapa da vida. In: COLÓQUIO INTERNACIONAL SOBRE GESTÃO UNIVERSITÁRIA NA AMERICA DO SUL, 11, Congresso Internacional IGLU, 2, Florianópolis, 7-9 de dezembro de 2011. Anais... Florianópolis, 2011, p. 1-13. Disponível em: <https://repositorio.ufsc.br/ bitstream/handle/123456789/26133/5.27. pdf?sequence=1>. Acesso em: 22 out. 2014.

FRANÇA, L. H. Repensando a aposentadoria com qualidade: um manual para facilitadores de programas de educação para aposentadoria em comunidades. Rio de Janeiro: Centro de Referencia e Documentação sobre Envelhecimento, Universidade Aberta da Terceira Idade - UERJ, 2002.

FREITAS, E. V. de; PY, L. Tratado de Geriatria e Gerontologia. 3. ed. Rio de Janeiro: Guanabara Koogan Ltda, 2011.

FREITAS, C. A. S. L. et al. Vivendo o envelhecer: vozes de um grupo de idosos. Revista de Enfermagem UFPE [on-line], Recife, v. 4, n. 1, p. 98-105, 2010. Disponível em: <http:// www.revista.ufpe.br/revistaenfermagem/ index.php/revista/article/view/533>. Acesso em: 21 jun. 2014.

GOLDMAN, S. N. Envelhecimento e gerações. Trabalho apresentado no Ciclo de Palestras e Vivências Para a Terceira Idade, Sesc Alagoas, 2004. 
INSTITUTO BRASILEIRO DE GEOGRAFIA E ESTATÍSTICA - IBGE. Contagem da população 2010. Disponível em: <http://www. ibge.gov.br/home/estatistica/populacao/censo2010/sinopse/default_sinopse.sht>. Acesso em: 24 jun. 2014.

RIGUEIRA JUNIOR, I. Sem deixar ninguém de fora. Diversa, UFMG, Belo Horizonte, v. 7, n. 16, nov. 2008. Disponível em: <https:// www.ufmg.br/diversa/16/index.php/diversidade>. Acesso em: 14 out. 2014.

LEBRÃ, M. L. Epidemiologia do envelhecimento. BIS:Bol. Inst. Saúde, São Paulo, n. 47, p. 23-26, abr. 2009. Disponível em: <http://periodicos.ses.sp.bvs.br/scielo.php?script=sci_ arttext\&pid=S1518-18122009000200006\&ln $\mathrm{g}=\mathrm{en} \& \mathrm{nrm}=\mathrm{iso}>$. Acesso em: 12 out. 2014 .

LIMA, M. L. C. de et al. Assistência à saúde dos idosos vítimas de acidentes e violência: uma análise da rede de serviços SUS no Recife (PE, Brasil). Ciênc. saúde coletiva, Rio de Janeiro, v. 15, n. 6, p. 2677-2686, set. 2010. Disponível em: <http://www.scielo.br/ scielo.php?script=sci_arttext\&pid=S1413$-81232010000600006 \& \operatorname{lng}=\mathrm{en} \& \mathrm{nrm}=\mathrm{iso}>$. Acesso em: 29 out. 2014.

MENDES, A. da C. G. et al. Assistência pública de saúde no contexto da transição demográfica brasileira: exigências atuais e futuras. Cadernos de Saúde Pública, Rio de Janeiro, v. 28, n. 5, p. 955-964, maio 2012. Disponível em: <http://www.scielo.br/scielo.php?pid= S0102-311X2012000500014\&script=sci_arttext. Acesso em: 10 out. 2014.

MORAIS, G. S. N.; COSTA, S. F. G. ; FONTES, W. D.; CARNEIRO, A. D. Comunicação como instrumento básico no cuidar humanizado em enfermagem ao paciente hospitalizado. Acta Paul Enferm, São Paulo, v. 22, n. 3, p. 323-327, 2009. Disponível em: <http:// www.scielo.br/pdf/ape/v22n3/a14v22n3.pdf. Acesso em: 16 out. 2014.

MOREIRA, P. A.; JALLES, M. P.; REINALDO, M. A. S. Quem gosta de mim sou eu: contradições acerca da percepção do idoso diante do processo de envelhecimento. Revis- ta de Enfermagem da UFPE [on line], Recife, v. 1, n. 1, p. 63-71, jul./set. 2007. Disponível em http://www.revista.ufpe.br/revistaenfermagem/index.php/revista/article/download/13-8773-1-/1256. Acesso em: 2 jul. 2014.

MINAYO, M. C. S. O desafio do conhecimento. Pesquisa qualitativa em saúde. 9. Reed. rev. e aprim. São Paulo: Hucitec; 2006.

NAVARRETE, M. L. V.; SILVA, M. R. F. Introdução às técnicas aplicadas em saúde. Tradução: SILVA, M. R. F. Recife: IMIP, 2009.

ROZENDO, A. S.; JUSTO, J. S.; CORREA, M. R. Protagonismo político e social na velhice: cenários, potências e problemáticas. Revista Kairós Gerontologia, São Paulo, v. 13, n. 1, p. 35-52, jun. 2010. Disponível em: <http://www. http://webcache.googleusercontent.com/search?q=cache:vC4lcRVC eUQJ:revistas.pucsp.br/index.php/kairos/ article/download $/ 4857 / 3438+\& c d=1 \&$ hl=pt-BR\&ct=clnk\&gl=br $>$. Acesso em: 13 out. 2014.

SANTIN, J. R.; BOROWSKI, M. Z. O idoso e o princípio constitucional da dignidade humana. Revista Brasileira de Ciência do Envelhecimento Humano, Passo Fundo, v. 5, n. 1, p. 141-153, jan./jun. 2008. Disponível em: <http://www.upf.br/seer/index.php/ rbceh/article/view/261/196>. Acesso em: 22 jun. 2014.

SANTOS, F. H.; ANDRADE, V. M.; BUENO, O. F. A. Envelhecimento: um processo multifatorial. Psicol. estud., Maringá, v. 14, n. 1, p. 3-10, jan./mar. 2009. Disponível em: <http:// www.scielo.br/scielo.php?script=sci_arttext \&pid=S1413-73722009000100002>. Acesso em: 15 out. 2014.

SANTOS, A. L.; SANTOS, S. F. O. Morbidade e mortalidade da população idosa do distrito federal. In: CIEGESI, 1, Encontro Científico do PNAP/UEG, 1, de 22 a 23 de Junho de 2012, Goiânia, Goiás. Anais eletrônicos..., Goiânia, 2012. p. 649-660. Disponível em: <http://www.anais.ueg.br/index.php/ciegesi/ article/view/1159/870>. Acesso em: 20 out. 2014. 
SILVA, M. da C. O processo de envelhecimento no Brasil: desafios e perspectivas. Textos Envelhecimento, Rio de Janeiro, v. 8, n. 1, p. 43-60,jan./abr. 2005. Disponível em: <http:// revista.unati.uerj.br/scielo.php?script $=$ sci arttext\&pid=S1517-59282005000100004\&ln $\mathrm{g}=$ pt\&nrm=iso $>$. Acesso em: 23 out. 2014.

SILVA, M. do R. de F.; YAZBEK, M. C. Proteção social aos idosos: concepções, diretrizes e reconhecimento de direitos na América Latina e no Brasil. $R$. Katál., Florianópolis, v. 17, n. 1, p. 102-110, jan./jun. 2014. Disponível em: <http://www.scielo.br/pdf/rk/v17n1/ a11v17n1.pdf>. Acesso em: 15 out. 2014.

VERAS, R. P. Em busca de uma assistência adequada à saúde do idoso: revisão da literatura e aplicação de um instrumento de detecção precoce e de previsibilidade de agravos. Cadernos de Saúde Pública, Rio de Janeiro, v. 19, n. 3, p. 705-715, maio/jun. 2003. Disponível em: <http://www.scielo.br/ scielo.php?script=sci_arttext\&pid=S0102$-311 X 2003000300003 \& \operatorname{lng}=\mathrm{en}>$. Acesso em: 2 jul. 2014.

VERAS, R. P. Experiências e tendências internacionais de modelos de cuidado para com o idoso. Ciência \& Saúde Coletiva, Rio de Janeiro, v. 17, n. 1, p. 231-238, 2012. Disponível em: <http://www.scielo.br/ scielo.php?script=sci_arttext\&pid=S1413$-81232012000100025 \& \operatorname{lng}=$ en\&nrm=iso $>$. Acesso em: 11 out. 2014. 